\title{
MODERN MEDICAL DEVICES AND HOSPITAL DECISION- MAKING: A REVIEW OF ETHICAL AND SOCIAL CONSIDERATIONS DURING THE MANUFACTURE AND THE USE OF ADVANCED MEDICAL DEVICES
}

\author{
Shudipta Choudhury ${ }^{1,2}$ \\ ${ }^{1}$ Vigilenz Medical Devices Sdn. Bhd., 308b Jalan Perindustrian Bukit Minyak 18, Penang Science Park, 11900 Penang, \\ Malaysia \\ ${ }^{2}$ Research Fellow, Lincoln University College, Petaling Jaya, Malaysia
}

\author{
Correspondense: \\ Shudipta Choudhury \\ Director, Vigilenz Medical Devices Sdn. Bhd., \\ 308 balan Perindustrian Bukit Minyak 18, \\ Penang Science Park, 11900 Penang, Malaysia \\ Research Fellow, Lincoln University College, \\ Petaling Jaya, Malaysia \\ Phone: +6045057346 \\ Email: s.choudhury@vigilenzmd.com
}

\begin{abstract}
Background: The adoption of technologically advanced medical devices assisted healthcare providers to examine and treat diseases. However, technological advancements could increase the threats to safety, security, and reliability of the devices from complications associated with manufacturing, functionality, and the clinical application of the devices.

Aim: To examine the safety threats, cost implication, and bioethical standards of the manufacturing processes and the functionality of advanced medical devices.

Subject and Methods: The study was a narrative review through a qualitative research methodology. The secondary data was gathered from online databases including ProQuest, ResearchGate, CINAHL/EBSCOhost, PubMed, and ScienceDirect, from books, journals, conference proceedings, and other web publications between 2007 and 2017.

Results:There were safety hazards from human errors in the interpretation and the use of the advanced medical devices. Equipment imperfections and poor processes of maintenance and procurement affected the effective functionality of these medical devices. Healthcare expenditure was high, Social and bioethical considerations, users' complaints and post-market surveillance were essential in ensuring the safety of the devices and the maintenance of quality life for the users.

Conclusion: Safety hazards and cost implications of the use of technologically advanced medical devices were significantly high Social and bioethical standards in the manufacturing of medical devices contributed towards the production of safer devices.
\end{abstract}

Keywords: Innovative medical devices, social and bioethical standards, healthcare costs, safety threats

\section{Introduction}

The financial evaluation of advanced medical technology has become the main element for decision-making on health budget allocations. The medical device industry evolved as the most dynamic field of medical innovations with many newer products being marketed each year (1). The diversity of technologically advanced medical devices led to increased scrutiny on the cost-effectiveness of the devices. Their emergence assisted healthcare professionals in providing quality services and reducing the amount of time in the examination and treatment of patients (2). Their development was beneficial for patients especially those with acute and chronic health conditions. Figure 1 presented an example of a technologically advanced 
medical device used by healthcare providers to treat cancer (3).

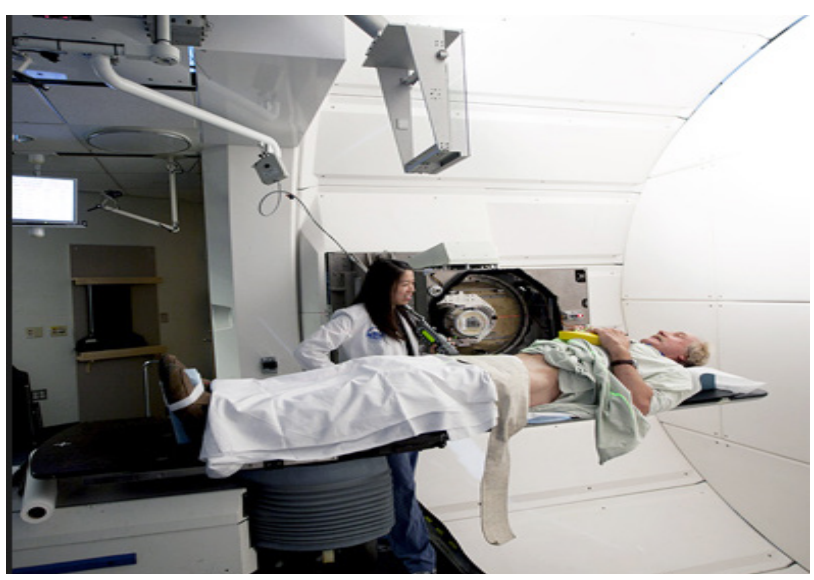

Figure 1: A technological advanced medical device for destroying cancer tissue using radiotherapy with a hyperthermia device. The patient was positioned for proton beam therapy where a beam of radiation is used to destroy cancer cells and tissues. Source: Skinner (2013) (3)

However, the failure of such devices could result in serious health complications and disastrous effects on the provision of care. The failure was associated with the poor calibration of the devices that led to poor treatment, improper medications, and adverse social and ethical problems that affected the quality of care and quality of life among the users of the medical devices (4).

\section{A Statement of the Problem}

The manufacturing and adoption of advanced medical devices played important roles in improving the quality of healthcare of patients with different health problems and reducing the fatalities from various chronic illnesses (5). The advancement in medical devices with the incorporation of computing software and hardware applications assisted clinicians in greater accuracy of diagnosis in patients and provided easier access to patient health records (6). However some presented catastrophic risks to the users (6). During the technological development and manufacturing of the medical devices, there was no consideration for the social and ethical concerns of such devices; of registration, licensing, and maintenance of standards (7). Due to the high demand for improved healthcare and effective response to health conditions, research had focused on the social and ethical considerations $(8,9)$. However, minimal research had been conducted concerning these social and ethical aspects, especially during their manufacture. There was a lack of transparency and of formal attention towards the assessment of effective and efficient utilization of resources in the manufacturing industry of these medical devices. Considerable research was thus needed to examine the key processes and the perceptions of social and ethical concerns of medical devices by healthcare professionals.

\section{The significance of the Study}

The study would provide an understanding of the ethical concerns in the adoption of technologically advanced medical devices for improved health care. The study would inform the manufacturers of the devices on issues ensuring compliance with the regulatory guidelines and standards. This would improve care together with the adoption of the changes in their use. Incorporating technology into medical devices is challenging because of the intrinsic complex nature of the devices.This study would form the basis for understanding the regulatory standards of technologically advanced devices during manufacturing in mitigating the safety risks to the user of the devices.

Exploring the social concerns of advanced medical devices in the study would provide information that regulatory bodies might-use when developing newer policies that would protect the users of medical devices from increased prices and safety concerns The study would help the implementation of the national policies with the reduction of the high prices that hospitals and users experienced with the use of the devices. The study would also allow policymakers of medical devices to formulate updated policies to minimize the uncertainties or adverse health incidents associated with the existing medical devices The study would provide the social and ethical guidelines that quality assurance professionals in companies that manufacture medical devices could adopt to improve the maintenance and effective clinical use of these medical devices.

\section{A Problem Statement and the Purpose of the Study}

Different technologically advanced medical devices assisted healthcare providers to examine and treat diseases. However, the technological advancements increased the threats to the safety, the security, and the reliability of the devices. This was the result-of the complications that arose during the manufacturing, the functionality, and the application of the devices for clinical treatment.

The main purpose of the study was to examine the compliance of healthcare manufacturers of these medical device concerning the social and ethical standards-during the manufacturing process.

The specific objectives were threefold: to determine the safety threats associated with the manufacturing of innovative technologically advanced medical devices; to establish the healthcare cost implications that resulted from the manufacturing of technologically advanced medical devices; and to explore the bioethical considerations for the development of new medical devices.

\section{Methodology}

Qualitative research with a literature review of the social and ethical aspects in the manufacturing of the advanced medical devices was conducted. Therefore, a qualitative research method was used in giving a detailed description 
and explanations of the research aims (10). A narrative review of the data from the different sources was applied to develop new theories through the application of prior assumptions.

\section{Sampling Considerations}

A study sample was usually based on demographic factors, geographic location, and clinical experiences (11). The targeted study sample was chosen based on the objectives of the research (12). No study sample was needed for the research. The study aimed to explain the research problem using existing information from previous studies in order to explore the research objective from a natural perspective.

\section{Tools for Collecting Data}

Secondary data was used in the study to address the research problem. Literature related to the topic under study was assessed, and relevant information obtained. The secondary data were obtained from different sources with an online search or retrieving existing information from web publications (13). The secondary data was obtained through online search from databases including ProQuest, ResearchGate, CINAHL/EBSCOhost, PubMed, and ScienceDirect. The other source used in this study was Google Scholar. The appropriate secondary data was gathered from scholarly sources such as books, peer-reviewed journals, web publications, conference proceedings, and other reliable sources with relevant information on the research topic. Using the abovementioned databases, old and current studies were used to collect secondary data which assisted in making comparisons between the previous studies and the updated versions of the research topic. This allowed extensive explanations of the research problem using the previous and the most current secondary data. The adoption of the secondary sources provided the basis for comparing the previous and current researches about the bioethical standards of medical device manufacturing processes.

\section{Procedures}

Online databases were used to find appropriate secondary data that explained the study problem. Articles used were those published from 2008-2017. Key phrases that contained keywords were developed to assist in retrieving the most suitable secondary data for the study. The main terms that were used to retrieve relevant information included "bioethical standards in the manufacturing of advanced medical devices", "social and ethical standards and the manufacturing of technologically advanced medical devices", and "ethical considerations of technologically advanced medical devices". The Boolean operators "AND" and "OR" were used in the online search and this helped in acquiring additional sources. For instance, the key phrases Bioethical standards AND manufacturing of advanced medical devices, OR bioethical considerations of medical devices were used. The development of the main terms and the use of Boolean operators in each of the databases helped in performing extensive research in order to get reliable sources that ensured the accomplishment of the research objectives developed.

\section{Results}

The study research identified articles that were relevant to the study. From assessments of the abstracts and full texts, several articles were identified while others were eliminated as indicated in Table 1 below.

Table 1: Description and number of articles used for the review

\begin{tabular}{|l|c|}
\hline Article description & Number \\
\hline All articles & 38 \\
\hline Screened & 23 \\
\hline Relevant articles after screening & 8 \\
\hline $\begin{array}{l}\text { Additional sources from the reference list } \\
\text { of all articles }\end{array}$ & 5 \\
\hline Reviewed articles for the narrative review & 13 \\
\hline
\end{tabular}

The objectives and findings of the articles used to guide the study were summarized in Table 2 below.

Table 2: Summary of objectives and findings of the reviewed articles. Source: self Safety Threats of Using Advanced Medical Devices in Hospitals

\begin{tabular}{|l|l|l|}
\hline $\begin{array}{l}\text { Article } \\
\text { author }\end{array}$ & Objectives & Findings \\
\hline $\begin{array}{l}\text { Kumar } \\
(2011)\end{array}$ & $\begin{array}{l}\text { To investigate how } \\
\text { pediatric care can be } \\
\text { made affordable } \\
\text { To find out how the } \\
\text { cost of innovations } \\
\text { can be reduced } \\
\text { To investigate } \\
\text { quality measures } \\
\text { for technologically } \\
\text { advanced medical } \\
\text { devices }\end{array}$ & $\begin{array}{l}\text { Cost-effective } \\
\text { measures like basic } \\
\text { infection control may } \\
\text { be used. } \\
\text { Standardization } \\
\text { of cardiac } \\
\text { surgery, catheter } \\
\text { interventions and } \\
\text { intensive care } \\
\text { practices to ensure } \\
\text { patients are well } \\
\text { cared of. }\end{array}$ \\
\hline $\begin{array}{l}\text { Sorenson } \\
\text { et al. } \\
\text { (2013) }\end{array}$ & $\begin{array}{l}\text { To identify the } \\
\text { relationship } \\
\text { between healthcare } \\
\text { technology } \\
\text { and increased } \\
\text { expenditures }\end{array}$ & $\begin{array}{l}\text { The relationship } \\
\text { between medical } \\
\text { technology and } \\
\text { spending is complex } \\
\text { The impact of } \\
\text { technology on costs } \\
\text { varies across various } \\
\text { technologies }\end{array}$ \\
\hline $\begin{array}{l}\text { Ciani et } \\
\text { al. (2016) } \\
\text { (8) }\end{array}$ & $\begin{array}{l}\text { To enlarge the } \\
\text { viewpoint on } \\
\text { innovation } \\
\text { in medical } \\
\text { technologies } \\
\text { To provide } \\
\text { healthcare policy- } \\
\text { makers with useful } \\
\text { insights }\end{array}$ & $\begin{array}{l}\text { An innovation of } \\
\text { medical devices has a } \\
\text { multidimensional and } \\
\text { perspective facet. } \\
\text { Policy-makers play an } \\
\text { important role in the } \\
\text { process of innovation } \\
\text { Tight regulations } \\
\text { reduce the expected } \\
\text { results of innovation }\end{array}$ \\
\hline
\end{tabular}


The study found that safety threats during the use of advanced medical devices were an area of great importance. Two articles retrieved showed that safety threats with undesirable health outcomes occurred due to the misadministration from medical device errors $(16,17)$. The study identified the technical defects, and human errors, the poor processes of maintenance and procurement of the advanced medical devices that led to adverse events and that affected the effectiveness and safety of the devices for the patients.(16). Malicious code injected into the medical system could alter the details of patients hence lead to misdiagnosis (17). Amoore (2014) mentioned that human errors from the inadequacy in the knowledge of the use of devices led to a case where a patient was not well-prepared before undergoing radiotherapy (16). As a consequence, the patient was hurt in the process.

Human errors also lead to safety threats with the use of advanced medical devices. These errors caused fatal and severe health injuries to the patients. The technical problems that arose with human errors in using medical devices led to higher incidences of deaths (18). Also, the misinterpretation of the essential outputs by the medical practitioners using the medical devices led to wrong decisions or actions which could contribute to the improper use of the devices. The failure to follow the procedures as prescribed by the manufacturers while using the medical devices and the limited training on the use of devices increase human errors that affected the delivery of highquality care (18). The presence of such errors with the use of medical devices required the manufacturers to work in collaboration with stakeholders, to investigate the possible incidences, and to provide effective solutions. This would help the healthcare givers and patients using the devices to follow the correct procedures for safe and quality care.

\section{Healthcare Cost Implications of Technologically Advanced Medical Devices}

The advanced medical technology is the main healthcare expenditure. Two articles were found that showed technological advanced medical devices as the key factors of healthcare expenditures $(15,19)$. The studies established that the need to develop advanced medical devices was costly and the adoption of such advances had significant financial implications. Healthcare organizations that had adopted newer medical technologies-had to restructure themselves so as to follow regulations hence making the whole adoption process costly. As such, medical innovation increased the costs to healthcare providers and healthcare consumers (19). Advances in medical technology and their applications across healthcare systems had become the key driver of health expenditure (20). The most critical elements that increased healthcare expenditure included the adoption and distribution of new drugs, equipment, and the delivery of healthcare systems. For instance, healthcare expenditure in the United States for medical technologies increased from \$27.4 in 2013 billion to \$2.9 trillion in 2017 (19). This expenditure was expected to continue to increase and would reduce the real income which was expected to diminish the total utility while increasing the costs, particularly to the low-income people (19). Figures 2 and 3 represented the cost paradox of healthcare technology in the United States between 1960 and 2006 and between 2006 and 2017.

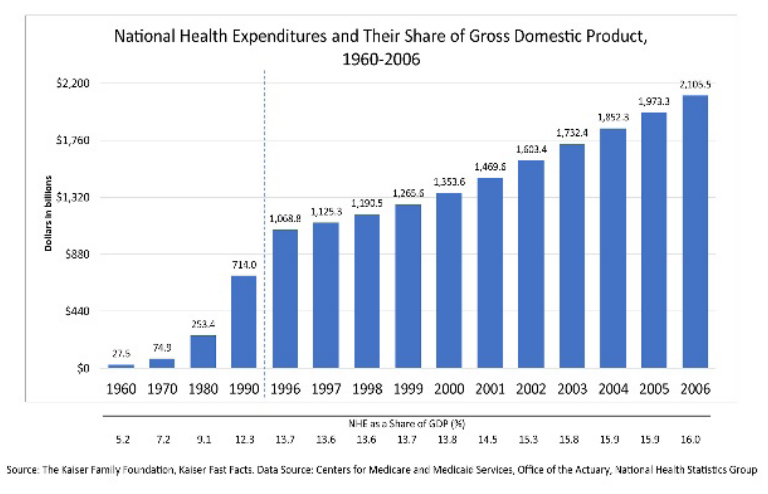

Figure 2: National Health Expenditure between 1960 and 2006. Source: Callahan (2017) (21)

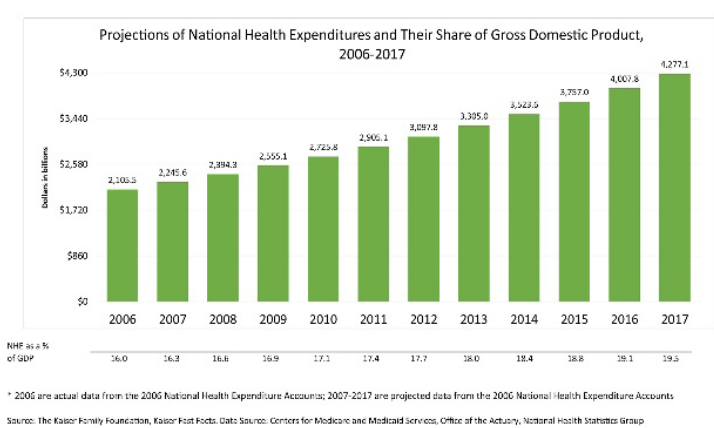

Figure 3: National Health Expenditure between 2006 and 2017. Source: Callahan (2017) (21)

In addition, the reimbursement and pricing of medical devices was a financial challenge. The adoption of modern medical devices included costs like acquisition costs and medical practitioners training costs. This was attributed to the fact that many patients were unable to pay the required amount for the medical services in hospitals (22). Patients who were supposed to undergo cancer treatments had to go to specific hospitals with an increase in transportation costs to and from their homes (3). Moreover, the treatment process using technologically advanced medical devices required the use of multiple devices that had to be paid for separately, and because most insurance covers did not cater for the devices, the patient might end up becoming bankrupt (3). Thus, delay in paying for the services could hinder the introduction of other newer medical technology and advanced devices to the global market (23). 


\section{Social and Bioethical Standards in the Manufacturing of Technologically Advanced Medical Devices}

Bioethical issues are the regulatory guidelines that were used by medical professionals and patients to make informed decisions during the delivery of healthcare services. These ethical issues were applied when delivering care to patients who were at the end stage of life, those who were terminally ill or the sick people visiting a healthcare facility (24). During the introduction of advanced medical devices to healthcare facilities, taking into account the ethical principles of beneficence, respect for autonomy, and non-maleficence was essential for improvement in quality care (25). The social and ethical considerations with a focus on ethical principles provided a comprehensive understanding of the regulatory policies that directed the manufacturing practices of any advanced medical devices. This helped the health facilities to ensure the devices were safe, reliable, accurate, and functioning effectively at the expected level of performance (26).

The adherence to legislation and standards that governed advanced medical devices was also a bioethical issue in the manufacturing of medical devices. The medical devices stakeholders including the manufacturers, distributors of the devices, and the users should work in collaboration with manufacturers to ensure adequate risk management and coordination of devices. This ensured safety considerations while producing and using the technologically advanced medical devices (27). Under the regulatory processes of medical devices, the manufacturers should also perform post-market surveillance of their products. The surveillance practice assisted in ensuring the effective monitoring of concepts related to the safety and the efficient use of the medical devices by the users (28). Security was also a bioethical consideration for manufacturers of advanced medical devices. Taking into account the risk management and security maintenance of the devices during the production process helped in assessing any interference that might affect the functionality of the devices (27). Reporting the health complications associated with advanced medical devices such as death and serious health deterioration is an ethical concern that the manufacturers should adhere to for the production of more stable and newer devices.

Reporting such cases allowed the manufacturers to take into consideration the thoughts and opinions of healthcare providers, patients, and other users of devices in order to make further adjustments to the devices. (29). Complaints regarding the use of medical devices should involve exhaustive and in-depth investigations in order to resolve the shortcomings in the device performance (30).

\section{Discussion}

In relation to the safety threats of advanced medical devices, the study found that the technological imperfection of advanced medical devices contributed to system failures. These system failures affected the functionality of the devices. These findings were consistent with the existing literature that the safety problems with the use of advanced medical devices such as equipment failure resulted from the materials used during the designing of the product and the electrical and thermal problems which necessitated the modification of the devices and further improvement to minimize the threats (31). The failures of the medical devices such as product defect resulted from poor designing and manufacturing of the product (31).

The study also revealed that human errors were the safety threats of advanced medical devices. The results showed that the misinterpretation and the lack of adequate training with the use of technologically advanced medical devices resulted in human errors that affected the delivery of safety and quality. These findings supported the study by Fries (2012) that physical abuse of the devices, spills, and excessive use of force when handling medical devices were among the significant human errors that affected the effectiveness of medical devices (32). Fries (2012) also showed that poor voltages and pneumatic connections and interchangeable electrical connections affected the functionality of the medical devices. These actions led to safety failure of the devices, becoming ineffective when used on patients (32).

The results also showed the cost implications of the advanced medical devices. The study revealed that advanced medical devices were expensive. The findings indicated that technologically advanced medical devices were the leading drivers for healthcare expenditures in healthcare organizations and to the patients. The results aligned with the findings by Sorenson et al. (2013) and Kumar (2011) that showed that the cost of treatment with the use of technologically advanced devices was high, and the rising cost was becoming the main concern for both the manufacturers and users of the devices $(14,15)$. The rapid changes in medical technology and the accessibility of high technological diagnostic and therapeutic equipment revolutionised the ways of delivering healthcare. In modern healthcare facilities, digital technology was driving the clinical practices (14). Therefore, hospitals, clinics, and other healthcare settings were depending on digital software to provide accurate patient health information. However, it was becoming increasingly expensive and unaffordable for some patients (14). Sorenson et al. (2013) mentioned that the use of advanced medical devices had led to lowered costs in terms of patients being treated faster and more effectively (15).

Bioethical standards in the manufacturing of technologically advanced medical devices were also examined. The results revealed that during the development of the medical devices, the manufacturers should take into considerations the ethical principles of beneficence, non-maleficence, and respect for autonomy as it helped them to ensure that the safety of users was maintained. The results added better insight into the article by Ross et al. (2010) that showed that taking into account the ethical principles provided an assurance towards the effective maintenance of the security, the safety, and the reliability of advanced medical 
devices by the users. Similarly, the results further explained that the stakeholders of medical devices should consider proper coordination and adequate risk management of the products during the production process. The study emphasized that this action was an ethical process of ensuring that the devices produced were safe and of high quality.

Reporting the health incidents that arose with the use of medical devices was also a bioethical consideration. The findings indicated that reporting complaints using the opinions of the users assisted manufacturers to adjust their products to meet the needs of the users. These findings were consistent with the results by Feijter et al. (2012) that indicated that analyzing the opinions of the users through post-market surveillance ensured the safety and effective performances of the medical devices (30).

\section{Conclusion}

Innovative technologically advanced medical devices had significant roles in promoting the diagnoses and treatment of different types of disease that affected the health of many people. Advanced medical technology was the main factor that drove the provision of high-quality care services. The adoption of advanced medical devices by healthcare professionals and other staff within the facilities ensured the support and the effective delivery of good care to all patients.

The healthcare cost implications resulted from the healthcare facilities, the manufacturing and the use of technologically advanced devices in the performance of a psychological process, the monitoring of a disease progression and the provision of adequate and appropriate treatment.

However, safety threats such as human errors and imperfection of the devices were common with the use of advanced medical devices. Security threats and equipment failure were present. Hence, bioethical standards were needed to ensure the safety and maintenance of the quality of life among users.

\section{Recommendations}

The study recommended that medical stakeholders including patients should report their experiences of risks with the use of advanced medical devices. The medical device policymakers should also provide better solutions with the use of fabrication materials during the manufacturing process to ensure the safe and effective use of the devices to maintain operator and patient safety.

\section{Competing interests}

The authors declare that they have no competing interests.

\section{References}

1. Kirisits A, Redekop WK. The economic evaluation of medical devices: Challenges ahead. Applied Health Economics and Health Policy. 2013;11(1):15-26.

2. McCaffery F, Burton J, Richardson I. Risk management capability model for the development of medical device software. Software Quality Journal. 2010; 18(1): 81-107.

3. Skinner J. The costly paradox of health-care technology; 2013. Available from: https://www. technologyreview.com/s/518876/the-costlyparadox-of-health-care-technology/

4. Lincoln JE. Lifecycle considerations for device software.JVT. 2012;18(1):15-21.

5. Gelijns AC, Russo MJ, Hong KN, Brown LD, Ascheim DD, Moskowitz AJ. Dynamics of device innovation: Implications for assessing value. Int J Technol Assess Health Care. 2013;29(4):365-73.

6. Neuman MR, Baura GD, Meldrum S, Soykan O, Valentinuzzi ME, Leder RS, et al. Advances in medical devices and medical electronics. Proc IEEE; 2012,100: 1537-50.

7. Alvarenga A, Tanev G. A Cybersecurity Risk Assessment Framework that Integrates Value-Sensitive Design. TIM Review. 2017;7(4):32-43.

8. Ciani O, Armeni P, Boscolo PR, Cavazza M, Jommi C, Tarricone R. De innovatione: The concept of innovation for medical technologies and its implications for healthcare policy-making. Health Policy Technol. 2016;5(1):47-64.

9. Shimanuki S, Saiki T. Technological diversity management of medical device enterprises. Journal of Strategy and Management. 2012;5(4):420-36.

10. William C. Research methods.JBER. 2007;5(3):65-72.

11. Banerjee A, Chaudhury S. Statistics without tears: Populations and samples. Ind Psychiatry J. 2010;19(1):60-5.

12. Martínez-Mesa, J., González-Chica DA., Duquia RP, Bonamigo RR, Bastos JL. Sampling: how to select participants in my research study? Anais Brasileiros de Dermatologia. 2016;91(3):326-30.

13. Tripathy JP. Secondary data analysis: Ethical issues and challenges. Iran J Public Health. 2013;42(12):1478-9.

14. Kumar RK. Technology and healthcare costs. Ann Pediatr Card. 2011;4(1):84-6.

15. Sorenson C, Drummond M, Khan BB. Medical technology as a key driver of rising health expenditure: disentangling the relationship. CEOR. 2013;5:223-34.

16. Amoore JN. A structured approach for investigating the causes of medical device adverse events. J Med Eng. 2014;2014:314138.

17. Golder S, Loke YK, Wright K, Norman G. Reporting of adverse events in published and unpublished studies of health care interventions: A systematic review. Plos Med. 2016;13(9):1-22. 
18. Dhillon BS. Medical equipment reliability: A review, analysis methods and improvement strategies. Int J Reliab Qual Saf Eng. 2011;18(4):391-403.

19. Roh CY, Kim S. Medical innovation and social externality.JOItmC. 2017;3(1):3-11.

20. Organization for Economic Co-operation and Development. OECD Health at a Glance: Europe 2010. Paris, France: http://dx.doi.org/10.1787/ health_glance-2010-en

21. Callahan D. Health care costs and medical technology. 2017. Available from: https://www.thehastingscenter. org/briefingbook/health-care-costs-and-medicaltechnology/

22. Ventola CL. Challenges in evaluating and standardizing medical devices in health care facilities. Pharm Ther. 2008;33(6):348-59.

23. 23. Bergsland J, Elle OJ, Fosse E. Barriers to medical device innovation. Med Devices. 2014;7:205-9.

24. Dennis D. Bioethics, euthanasia, and physicianassisted suicide. In D. Dennis (Ed.), Living, dying, grieving. Sudbury, MA: Jones and Bartlett; 2009:3750.

25. Ross S, Weijer C, Gafni A, Ducey A, Thompson C, Lafreniere R. Ethics, economics and the and adoption of new medical devices: case studies in pelvic floor surgery. BMC Med Ethics. 2010;11(1):14.

26. Jamshidi A, Rahimi SA, Ait-kadi D, Bartolome AR. Medical devices inspection and maintenance: A literature review. In IIE Annual Conference. Proceedings. Institute of Industrial EngineersPublisher; 2014:3895.

27. Sametinger J, Rozenblit J, Lysecky R, Ott P. Security challenges for medical devices. Commun ACM. 2015;58(4):74-82.

28. Rajan PV, Kramer DB, Kesselheim, AS. Medical device post approval safety monitoring: Where does the United States stand? Circ Cardiovasc Qual Outcomes. 2015;8(1):124-31.

29. Kreiwall TJ. Ethics of medical device safety. J Long Term Eff Med Implants. 2008;18(2):167-74.

30. Feijter JM, Grave WS, Muijtjens AM, Scherpbier AJ, Koopmans, RP. A comprehensive overview of medical error in hospitals using incident-reporting systems, patient complaints and chart review of inpatient deaths. Plos One. 2012;7(2):1-7.

31. Subhan A. Part X: Engineering assessment of medical device failures. J Clin Eng. 2009;34(3):115.

32. Fries RC. Reliable design of medical devices. 2012; CRC Press. 